\title{
Currículo e manuais escolares em contexto de flexibilidade curricular. Estudo de processos de recontextualização
}

\author{
Sílvia Calado \& Isabel Pestana Neves \\ Universidade de Lisboa, Portugal
}

\begin{abstract}
Resumo
O estudo centra-se na mensagem de dois manuais escolares de Ciências Naturais do $3^{\circ} \mathrm{CEB}$ e na caracterização dos processos de recontextualização que ocorrem na mensagem do currículo aquando da elaboração daqueles, tendo em conta características pedagógicas específicas. O estudo apresenta fundamentos epistemológicos, psicológicos e sociológicos, constituindo o modelo do discurso pedagógico de Bernstein a principal estrutura conceptual da investigação. Seguiu-se uma metodologia mista, mantendo-se uma dialéctica entre o teórico e o empírico. Os resultados mostram que a mensagem dos manuais veicula baixa representatividade da metaciência e baixo grau de relações intradisciplinares, de exigência conceptual e de explicitação dos critérios de avaliação, sobretudo a do manual mais seleccionado. Verifica-se um elevado grau de recontextualização da mensagem do currículo. Estes resultados levantam questões sobre o nível da aprendizagem científica em contexto de flexibilidade curricular, dado o maior controlo conferido aos autores de manuais/professores.
\end{abstract}

Palavras-chave

Manuais escolares; Educação científica; Processos de recontextualização; Flexibilidade curricular

\section{Introdução}

No contexto da reorganização curricular do sistema educativo português do ensino básico, que teve início no ano escolar de 2001/2002 
(Decreto-Lei 6/2001), foram elaborados dois documentos curriculares orientadores do processo de ensino/aprendizagem: Competências Essenciais (Departamento de Educação Básica [DEB], 2001), que define um conjunto de competências consideradas essenciais no âmbito do desenvolvimento do currículo nacional para o ensino básico, e Orientações Curriculares (DEB, 2002), cujo texto orienta a gestão dos conhecimentos e a implementação de experiências educativas, estando estruturado em torno de quatro temas organizadores: "Terra no Espaço", "Terra em Transformação", "Sustentabilidade na Terra" e "Viver melhor na Terra".

Estes documentos surgem num contexto de flexibilidade curricular dando "a possibilidade de cada escola, dentro dos limites do currículo nacional, organizar e gerir autonomamente todo o processo de ensino/aprendizagem [que] deverá adequar-se às necessidades diferenciadas de cada contexto escolar, podendo contemplar a introdução no currículo de componentes locais e regionais" (DEB, 1999, p. 7). Neste contexto, existe então um espaço privilegiado para a autonomia das escolas e dos professores, que passam a ter um papel fundamental na construção do currículo (Flores \& Flores, 2000).

No desenvolvimento do seu trabalho, o professor não tem por hábito contactar directamente com os documentos curriculares, recorrendo usualmente ao manual escolar (Pacheco, 2001; Santos, 2001). O manual constitui, assim, o principal mediador curricular, desempenhando um papel fundamental já que comporta e estrutura um conjunto de informações formais para o contexto de transmissão/aquisição, determinando os conhecimentos que são discutidos na sala de aula e a forma como são ensinados. Os manuais têm um forte impacto no que se passa nas salas de aula: para os alunos representam as próprias disciplinas e para os professores e pais representam um referencial estável, duradouro das matérias escolares (Valverde, Bianchi, Wolfe, Schmidt, \& Houang, 2002).

Uma vez que os professores tendem a seguir os manuais de forma "obediente" (Squire, 1992), o currículo 'construído' pelo professor tende a reflectir mais a mensagem do manual escolar adoptado na escola do que a mensagem dos documentos curriculares oficiais. Por sua vez, os manuais escolares tendem a ser elaborados, principalmente, com base nas directrizes curriculares específicas da respectiva disciplina (Neves \& Morais, 2006). 
Tendo presente o grau de autonomia dos vários agentes envolvidos no processo de ensino/aprendizagem (entre os quais, autores de manuais escolares e professores), torna-se necessário compreender as transformações que ocorrem na mensagem dos vários documentos orientadores daquele processo (documentos curriculares, manuais), uma vez que diferentes concepções sobre o que valorizar no ensino das ciências poderão conduzir "à 'construção' de uma diversidade de programas que, no pior dos cenários, corresponderão a textos com maior ou menor 'qualidade' consoante os públicos a que se destinam e a competência dos vários professores" (Neves \& Morais, 2006, p. 88).

O estudo a que se refere este artigo integra uma investigação mais ampla (Calado, 2007) que envolveu a análise do discurso pedagógico veiculado no currículo de Ciências Naturais do $3^{\circ}$ Ciclo do Ensino Básico e em manuais escolares de Ciências Naturais, relativamente ao tema organizador "Viver melhor na Terra", e ainda a análise dos processos de recontextualização que ocorrem entre estes níveis de desenvolvimento curricular. Estas análises tiveram como foco quatro características pedagógicas que têm sido apontadas por alguns estudos (e.g. McComas \& Olson, 1998; Morais \& Miranda, 1995; Morais \& Neves, 2009; Pires, Morais, \& Neves, 2004) como promotoras do desenvolvimento da literacia científica, nomeadamente a necessidade de, no ensino das ciências, ser abordado o processo de construção da ciência, serem estabelecidas relações intradisciplinares (intradisciplinaridade), o nível de exigência conceptual ser elevado e os critérios de avaliação serem explícitos.

Este artigo foca-se na análise do discurso pedagógico expresso em dois manuais escolares de Ciências Naturais do $3^{\circ}$ Ciclo do Ensino Básico, relativamente às quatro características pedagógicas anteriormente mencionadas e, através desta análise, discutem-se os processos de recontextualização que ocorrem na elaboração de manuais escolares e que transformam, em maior ou em menor grau, a mensagem contida no discurso pedagógico oficial. Pretende-se investigar o seguinte problema: Em contexto de flexibilidade curricular, que recontextualização ocorre na mensagem dos documentos oficiais referentes ao ensino das ciências quando ela é traduzida na mensagem expressa em manuais escolares? 
Com base neste problema, estabeleceram-se os seguintes objectivos: a) analisar a mensagem de manuais escolares relativamente às quatro características pedagógicas seleccionadas; b) caracterizar a extensão e 0 sentido da recontextualização presente nos manuais escolares em relação aos documentos curriculares; e c) reflectir sobre as consequências da recontextualização do discurso pedagógico na aprendizagem científica de todos os alunos em contexto de flexibilidade curricular.

A Figura 1 apresenta as relações analisadas: estão presentes os campos de recontextualização oficial e pedagógica onde têm lugar, respectivamente, a produção dos documentos curriculares (discurso pedagógico oficial - DPO) e de manuais escolares (discurso pedagógico de reprodução - DPR).

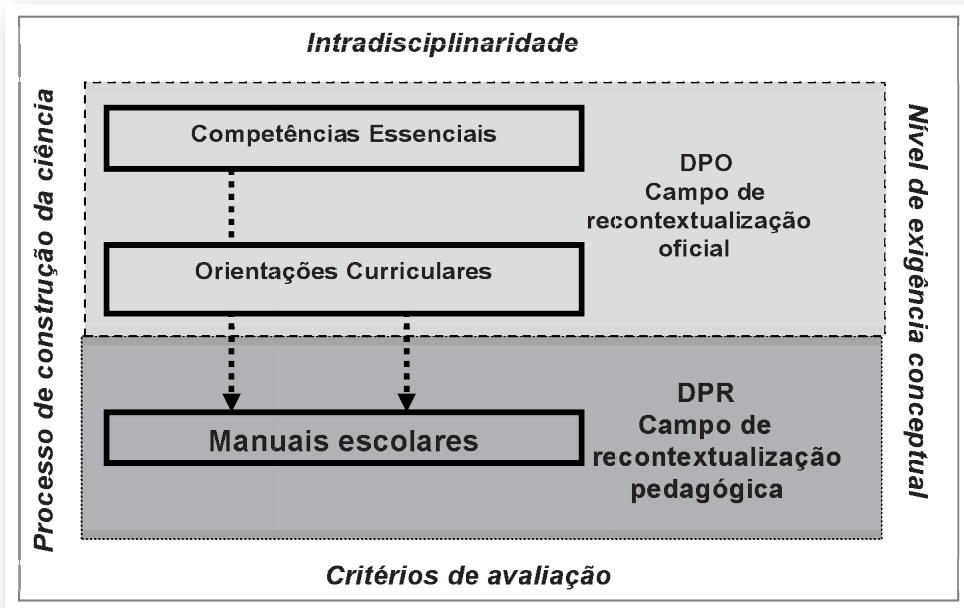

Figura 1 - Esquema geral das relações analisadas

\section{Fundamentação teórica}

Epistemologicamente, o presente estudo baseia-se no modelo da construção da ciência de Ziman (1984), que considera cinco dimensões metacientíficas: filosófica, histórica, psicológica, sociológica interna e sociológica externa. A dimensão filosófica da ciência refere-se aos aspectos metodológicos usados na investigação científica. Já a dimensão histórica 
realça o carácter de arquivo da ciência e confere-lhe uma perspectiva de actividade dinâmica, que progride ao longo do tempo. A dimensão psicológica da ciência diz respeito às características pessoais dos cientistas, relevantes no trabalho que estes desenvolvem. Quanto à dimensão sociológica interna, está relacionada com as relações sociais que se estabelecem e que se desenvolvem entre os cientistas, no seio da comunidade científica, onde se expressam interesses, criam-se expectativas, ocorrem tensões e conflitos. Por fim, a dimensão sociológica externa reflecte os efeitos sociais dos avanços da ciência, como os dilemas, os interesses, as limitações e, segundo Ziman (1984), integra a relação biunívoca entre a ciência, a tecnologia e a sociedade.

Numa vertente psicológica, o estudo tem em consideração as ideias de Vygotsky (1978), nomeadamente, sobre a importância do processo de ensino/aprendizagem estar estruturado de forma a promover um elevado nível de exigência conceptual. Em termos sociológicos, o estudo baseia-se no modelo do discurso pedagógico de Bernstein (1990, 2000), o qual constituiu a principal estrutura conceptual desta investigação. Este modelo possibilita a análise do discurso pedagógico veiculado em textos produzidos nos vários níveis do sistema educativo, bem como a análise dos processos de recontextualização que ocorrem entre esses níveis.

De acordo com o modelo do discurso pedagógico de Bernstein (1990, 2000), na produção e reprodução do discurso pedagógico são considerados três níveis de análise - o de geração, o de recontextualização e o de transmissão - em que nos dois primeiros níveis ocorre a produção do discurso pedagógico e no terceiro ocorre a sua reprodução. É no nível de recontextualização, no campo de recontextualização oficial, onde se inclui o Ministério de Educação, que é produzido o discurso pedagógico oficial (DPO) que se encontra expresso em vários textos, como o Currículo Nacional veiculado nas Competências Essenciais e nas Orientações Curriculares para o $3^{\circ}$ Ciclo do Ensino Básico. Este discurso entra no campo de recontextualização pedagógica, onde se incluem, por exemplo, departamentos de educação, escolas de formação de professores e instituições de produção de materiais pedagógicos, como manuais escolares. Através de novos processos de recontextualização, é produzido o discurso que é veiculado nos manuais escolares, o discurso pedagógico de reprodução 
(DPR) ${ }^{1}$. O discurso pedagógico é reproduzido ao nível da sala de aula, podendo ainda ser sujeito a novas recontextualizações que dependem do contexto específico da escola e da prática do professor.

Consoante a recontextualização do discurso pedagógico ao nível dos campos de recontextualização oficial e pedagógica, aquele discurso irá veicular uma determinada mensagem caracterizada por relações de poder e de controlo entre várias categorias, nomeadamente discursos (e.g. relações intradisciplinares e interdisciplinares), espaços (e.g. professor/aluno) e sujeitos (e.g. Ministério de Educação/autores de manuais e professores, professor/aluno). Para caracterizar as diversas formas de poder e de controlo são usados os conceitos de classificação e de enquadramento, respectivamente (Bernstein, 1990).

No âmbito de uma análise curricular, a relação entre sujeitos pode ser referente às relações de poder e de controlo entre o Ministério da Educação e os autores de manuais escolares/professores, bem como entre os autores de manuais escolares e os professores. Nestas relações, o Ministério da Educação apresenta um estatuto sempre mais elevado que os autores de manuais escolares/professores, ocorrendo fronteiras nítidas entre 0 transmissor (Ministério da Educação) e os aquisidores (autores de manuais escolares/professores), isto é, valores fortes de classificação. Esta tendência é igualmente verificada na relação entre os autores de manuais escolares e os professores. No entanto, podem-se constatar diferentes valores de enquadramento, sendo que os valores fortes ocorrem quando as categorias de maior estatuto (Ministério da Educação ou autores de manuais escolares consoante a relação considerada) assumem o controlo da relação. Os valores fracos registam-se quando as categorias de menor estatuto (autores de manuais ou professores consoante a relação considerada) detêm algum controlo.

O texto dos manuais escolares (DPR), através dos componentes constituintes e da sua organização, veicula então uma determinada mensagem sociológica para o professor/aluno. Tal como os manuais escolares reflectem as interpretações que os respectivos autores fazem dos documentos curriculares, também os professores tomam decisões e fazem interpretações da mensagem dos manuais escolares, e dos próprios documentos curriculares, de acordo com as suas concepções 
pedagógicas/ideológicas e sob influências externas (económicas, ideológicas e académicas). Ou seja, um manual pode incorporar uma mensagem diferente da mensagem dos documentos curriculares, ou mesmo diferente daquela que os autores se propunham passar, e os professores podem desenvolver um contexto de ensino/aprendizagem diferente daquele que os manuais preconizam. Neste sentido, é importante que os autores de manuais escolares (em geral, professores), ao elaborarem os textos, considerem que as aprendizagens que aqueles veiculam poderão traduzir-se em determinadas relações sociais e que essas aprendizagens resultam de relações sociais reguladas pelos documentos curriculares.

Num contexto de flexibilidade curricular, em que a escola tem mais autonomia, os autores de manuais escolares e professores dispõem de mais controlo sobre várias opções para o contexto de ensino/aprendizagem - por exemplo, o controlo sobre a selecção e a sequência dos conhecimentos a leccionar. Esta situação favorece o aparecimento de um potencial espaço de mudança que será tanto maior quanto maior for o grau de recontextualização sofrido pelo discurso pedagógico. Este espaço de mudança permite ao professor, por exemplo, a implementação de várias modalidades de prática pedagógica que, por sua vez, podem provocar alterações no padrão diferencial do sucesso escolar dos alunos. Com efeito, num contexto de flexibilidade curricular, a maior autonomia da escola/professor pode representar potencialidades, mas também limitações, para uma efectiva alfabetização científica de todos os alunos.

Considerando que, em Portugal, para um mesmo programa é editada uma variedade de manuais de diferentes autores, vão surgir manuais com diferentes mensagens sociológicas, com diferentes relações sociais de poder e de controlo. A selecção de manuais pelos professores (isto é, a selecção de uma mensagem) poderá traduzir diferentes concepções pedagógicas/ ideológicas dos professores, que, por sua vez, poderão induzir desigualdades na aprendizagem dos alunos (Neves, 1991). O uso do manual escolar tem sido uma prática recorrente no ensino das ciências (Santos, 2001), sendo que o modo como os professores o valorizam influencia a forma como os alunos perspectivam a natureza da ciência (Castro \& Cachapuz, 2005).

De um ponto de vista de desenvolvimento curricular, Pacheco (2001) salienta alguns aspectos positivos e outros negativos sobre o papel dos 
manuais escolares. Como aspectos positivos refere a diversificação de actividades, a motivação dos alunos com o aspecto gráfico e icónico e a oferta de um guia de estudos, com possibilidades de utilização autónoma. Em termos de aspectos negativos, destaca o facto de os manuais criarem hábitos de rotinização de práticas lectivas, de levarem à uniformização curricular e a um controlo implícito sobre os professores. Também Santos (2001), tendo a percepção da posição de destaque deste material curricular no ensino das ciências, refere algumas influências daquele, das quais se destacam: a selecção e sequência dos conhecimentos que, ao serem entendidos como "naturais", oferecem poucas oportunidades de abertura a outras vias; a lacuna de um quadro conceptual de referência, que poderá conduzir a um saber em mosaico e ao recurso a simplificações excessivas que contribuem para a fragmentação do saber; a aceitação da 'resposta certa' tal como aparece no manual; e a atribuição de um estatuto periférico e pouco claro às interacções entre ciência, tecnologia e sociedade.

Neste estudo, a análise das aprendizagens que são privilegiadas no discurso pedagógico veiculado em manuais escolares incidiu sobre o grau de complexidade das competências (metacientíficas e científicas) e dos conhecimentos (metacientíficos e científicos), sobre o grau de intradisciplinaridade (entre conhecimentos científicos e metacientíficos e entre diferentes conhecimentos científicos) e sobre o grau de explicitação dos critérios de avaliação (quanto aos conhecimentos metacientíficos e quanto às relações intradisciplinares), quando se considera a relação entre autores de manuais escolares e professores.

De acordo com McComas, Clough, e Almazroa (1998), um objectivo central no ensino das ciências deverá ser levar os alunos a compreender a natureza da ciência, os seus pressupostos, valores, finalidades e limitações. A abordagem à natureza da ciência - processo de construção da ciência - no ensino das ciências aponta para um ensino que motiva os alunos para a aprendizagem científica, desenvolve o pensamento crítico, esbate as fronteiras entre as ciências e as metaciências, analisa questões de cariz político, económico, ético e social da ciência e da tecnologia, e promove a alfabetização científica de todos para que possam exigir dos diferentes poderes decisões fundamentadas (Fontes \& Silva, 2004). 
Outros estudos (e.g. Domingos, 1989; Morais \& Neves, 2003; Pires, Morais, \& Neves, 2004) têm revelado que, para a promoção da literacia científica de todos os alunos, o contexto de ensino/aprendizagem deve basear-se, entre outras características, numa forte intradisciplinaridade, num elevado nível de exigência conceptual e em critérios de avaliação explícitos. A necessidade do processo de ensino/aprendizagem promover um elevado nível de exigência conceptual é também explicada pelo trabalho de Vygotsky (1978), ao referir que a instrução deverá ir mais além do nível de desenvolvimento cognitivo dos alunos, no sentido de proporcionar o desenvolvimento de processos mentais elevados. O elevado nível de exigência conceptual no contexto de ensino/aprendizagem pode ser estabelecido através da articulação entre conhecimentos, a qual leva a uma compreensão de conceitos de ordem elevada, com maior poder de descrição, explicação, previsão e transferência (Morais, 2002). Por sua vez, um grau elevado de intradisciplinaridade contribui para que o ensino das ciências se desenvolva conforme a integração que caracteriza a estrutura hierárquica do conhecimento científico² (Bernstein, 1999).

Num contexto de elevado nível de exigência conceptual, é igualmente fundamental tornar os critérios de avaliação explícitos para todos os alunos, ou seja, explicitar o texto pretendido, de forma a promover uma efectiva alfabetização científica. Tal como Morais e Miranda (1995) referem:

Os critérios tornam o aquisidor capaz de compreender o que é uma comunicação, uma relação social e uma posição legítima ou ilegítima. Admitese então, na medida em que a compreensão desses critérios contribui para a produção do texto legítimo, que a aquisição dos critérios de avaliação é um factor que influencia o aproveitamento diferencial dos alunos (p. 40).

Neste sentido, na prática pedagógica do professor, assim como nos manuais escolares, deve estar explícito o que se pretende no processo de ensino/aprendizagem.

\section{Metodologia}

\section{Aspectos gerais}

Neste estudo procedeu-se a uma análise documental, enquadrada numa abordagem metodológica com características de uma metodologia mista de investigação (e.g. Tashakkori \& Creswell, 2007; Morais \& Neves, 
2007). A orientação metodológica geral deste estudo foi de índole racionalista (mais associada a metodologias quantitativas) pelo facto de se ter recorrido a um quadro teórico de referência, nomeadamente a teoria de Bernstein, para orientar a investigação. Além disso, para a construção dos instrumentos de análise dos documentos estabeleceram-se, a priori, com base em elementos teóricos, as categorias e os indicadores de análise relacionados com as características pedagógicas seleccionadas. No entanto, para 0 estabelecimento dos descritivos foram considerados os dados empíricos obtidos nos estudos exploratórios efectuados nos documentos (característica mais associada às metodologias qualitativas), procurando-se assim construir categorias mais apropriadas ao contexto da análise. Ao nível da análise dos dados, seguiram-se procedimentos metodológicos fundamentalmente de natureza qualitativa, tendo-se procedido a uma análise interpretativa.

A dialéctica entre o teórico e o empírico que se manteve no estudo conduziu à construção de instrumentos de análise baseados na realidade em estudo e no quadro teórico de suporte. A manutenção desta dialéctica foi possível dado o rigor conceptual da teoria de Bernstein que, com uma linguagem de descrição interna possuidora de gramáticas fortes, permite o desenvolvimento de linguagens de descrição externa que, por sua vez, possibilitam a orientação de análises empíricas mais sistematizadas. Tal como Morais e Neves (2007) defendem:

Rejeita-se quer a análise do empírico sem uma base teórica, quer a utilização de teoria que não permita a sua transformação com base no empírico (p. 78).

Para este estudo foram escolhidos os dois manuais escolares (MA e MB) mais seleccionados no ano escolar $2004 / 2005^{3}$ quanto ao tema organizador "Viver melhor na Terra" de Ciências Naturais do $3^{\circ}$ Ciclo do Ensino Básico e, no âmbito deste tema organizador, foi estudado o tópico programático "Organismo humano em equilíbrio". A escolha do tema organizador tem inerente o facto de, na reorganização curricular de 2001, ressurgir a atribuição de carga horária para a disciplina de Ciências Naturais ao nível do $9^{\circ}$ ano de escolaridade, sendo que o tema "Viver melhor na Terra" é o que tem sido desenvolvido a esse nível, isto é, no último ano de escolaridade do $3^{\circ}$ Ciclo do Ensino Básico. A selecção do tópico "Organismo humano em equilíbrio" teve a ver com o facto de constituir um dos tópicos com maior representatividade nos manuais seleccionados. 
Em termos da organização do texto dos manuais, estabeleceram-se quatro secções que permitiram categorizar toda a informação destes (conhecimentos, finalidades, orientações metodológicas e avaliação). Procedeu-se à fragmentação do texto dos manuais em partes analisáveis - as unidades de análise $(\mathrm{UA})^{4}$-, determinando-se que uma unidade de análise corresponde a um excerto do texto que, no seu conjunto, tem um determinado significado semântico.

Tal como referido anteriormente, a dialéctica constante entre o teórico e o empírico sustentou reformulações nas UA e nos instrumentos de análise construídos, conduzindo a uma maior consistência entre os objectivos da investigação e a recolha de dados. Por outro lado, também os resultados da análise foram aferidos, independentemente, por outra investigadora, familiarizada com o enquadramento teórico do estudo.

\section{Instrumentos de análise de manuais escolares}

A análise de manuais escolares (DPR) teve como objectivos verificar, em termos das quatro características pedagógicas em estudo - construção da ciência, intradisciplinaridade, nível de exigência conceptual e critérios de avaliação -, qual a mensagem que aqueles veiculam e caracterizar os processos de recontextualização que ocorrem no DPR relativamente ao currículo (DPO). Assim, foi necessário proceder-se, numa primeira fase do estudo, à elaboração, pilotagem e aplicação de instrumentos ${ }^{5}$ para a análise da mensagem sociológica veiculada no currículo (DPO ${ }^{6}$, expresso nos documentos Competências Essenciais e Orientações Curriculares. Estes instrumentos foram adaptados para serem aplicados ao contexto dos manuais escolares e, assim, proceder-se à caracterização dos processos de recontextualização que ocorrem entre os dois níveis de análise. Os ajustamentos feitos nos instrumentos permitiram a comparação entre as duas mensagens, em que os descritivos dos instrumentos mantiveram a conceptualização equivalente aos vários graus considerados.

Os instrumentos usados no estudo das características pedagógicas em foco foram elaborados com base em instrumentos desenvolvidos em investigações anteriores (e.g. Castro, 2006; Neves \& Morais, 2001). Para a caracterização do processo de construção da ciência foram elaborados dois 
instrumentos: um com uma especificação de conhecimentos e de competências metacientíficos que serviu de complemento a um outro destinado a avaliar o nível de conceptualização do domínio metacientífico. Para o estudo da intradisciplinaridade foram também construídos dois instrumentos: um de avaliação do grau de relação entre conhecimentos científicos e metacientíficos e outro de avaliação do grau de relação entre diferentes conhecimentos científicos. A caracterização do nível de exigência conceptual foi feita com base no cálculo de um índice compósito que integrou três parâmetros: grau de complexidade de competências cognitivas científicas; grau de complexidade de conhecimentos científicos; e grau de intradisciplinaridade entre diferentes conhecimentos científicos. Neste sentido, foi necessário elaborar mais dois instrumentos: um para a caracterização do grau de complexidade das competências e outro para a caracterização do grau de complexidade dos conhecimentos. Por fim, para a análise do grau de explicitação dos critérios de avaliação, foram elaborados três instrumentos: um de avaliação do grau de explicitação dos conhecimentos metacientíficos e dois de avaliação do grau de explicitação das relações intradisciplinares supracitadas.

A caracterização do processo de construção da ciência baseou-se em conceitos relativos às cinco dimensões da construção da ciência do modelo de Ziman (1984): filosófica, histórica, psicológica, sociológica interna e externa. Neste âmbito, consideraram-se graus de complexidade de conhecimentos metacientíficos, relativos a cada dimensão da construção da ciência (conhecimentos de ordem simples e de ordem complexa), e considerou-se a presença/ausência de competências cognitivas metacientíficas referentes a cada uma das cinco dimensões, sem, contudo, estarem comprometidas com os respectivos conceitos (isto porque verificouse que, geralmente, as competências são exploradas sem estar prevista a sua relação com a construção da ciência). Para cada dimensão estabeleceu-se uma escala de quatro graus (G1, G2, G3 e G4) de complexidade crescente 7 .

Segue-se um excerto do instrumento de caracterização do nível de conceptualização do domínio metacientífico, quando se considera a dimensão filosófica (Tabela I), e duas unidades de análise classificadas de acordo com a escala deste instrumento. 
Tabela I - Excerto do instrumento de caracterização da construção da ciência (dimensão filosófica)

\begin{tabular}{|c|c|c|c|}
\hline Grau 1 & Grau 2 & Grau 3 & Grau 4 \\
\hline $\begin{array}{l}\text { Não são referidos } \\
\text { conhecimentos } \\
\text { relativos à } \\
\text { dimensão } \\
\text { filosófica da } \\
\text { ciência, nem se } \\
\text { prevê a sua } \\
\text { relação no } \\
\text { desenvolvimento } \\
\text { de competências } \\
\text { associadas a esta } \\
\text { dimensão. }\end{array}$ & $\begin{array}{l}\text { São referidos } \\
\text { conhecimentos de } \\
\text { ordem simples } \\
\text { relativos à } \\
\text { dimensão filosófica, } \\
\text { não se prevendo a } \\
\text { sua relação no } \\
\text { desenvolvimento } \\
\text { de competências } \\
\text { associadas a esta } \\
\text { dimensão } \\
\text { e/ou } \\
\text { Está previsto o } \\
\text { desenvolvimento } \\
\text { de competências } \\
\text { associadas à } \\
\text { dimensão filosófica } \\
\text { da ciência, mas } \\
\text { não a sua relação } \\
\text { com a construção } \\
\text { da ciência. }\end{array}$ & $\begin{array}{l}\text { São referidos } \\
\text { conhecimentos } \\
\text { de ordem } \\
\text { complexa } \\
\text { relativos à } \\
\text { dimensão } \\
\text { filosófica, não se } \\
\text { prevendo a sua } \\
\text { relação no } \\
\text { desenvolvimento } \\
\text { de competências } \\
\text { associadas a } \\
\text { esta dimensão. }\end{array}$ & $\begin{array}{l}\text { São referidos } \\
\text { conhecimentos } \\
\text { de ordem } \\
\text { complexa } \\
\text { relativos à } \\
\text { dimensão } \\
\text { filosófica, } \\
\text { prevendo-se a } \\
\text { sua relação no } \\
\text { desenvolvimento } \\
\text { de competências } \\
\text { associadas a } \\
\text { esta dimensão. }\end{array}$ \\
\hline
\end{tabular}

\section{Unidades de análise}

A renovação do ar nos pulmões ou a ventilação pulmonar compreende a inspiração e a expiração (Manual B. Secção Conhecimentos) - Grau 1.

Decorrente da abordagem efectuada fica a opção de, neste momento ou posteriormente, ser efectuada a observação/dissecação de órgãos do sistema nervoso central (Manual B. Secção Orientações metodológicas) - Grau 2.

A primeira unidade não faz referência a conhecimentos metacientíficos, apenas apresentando conhecimentos científicos. Na segunda unidade há referência a competências associadas à dimensão filosófica (e.g. observação) sem que seja estabelecida qualquer relação com o processo de construção da ciência.

$\mathrm{Na}$ análise da intradisciplinaridade, foram considerados fundamentos teóricos sobre o significado das relações intradisciplinares em função do 
conceito de 'classificação' da teoria de Bernstein (1990). Através destes pressupostos teóricos, estabeleceu-se uma escala de quatro graus de classificação $\left(\mathrm{C}^{++}, \mathrm{C}^{+}, \mathrm{C}^{-}\right.$e $\left.\mathrm{C}^{--}\right)$e construíram-se descritivos, relativos a cada secção dos manuais, sendo que valores fortes de classificação correspondem a fronteiras bem definidas e valores fracos traduzem-se no esbatimento das fronteiras entre discursos. Para a caracterização do grau de intradisciplinaridade entre conhecimentos científicos e metacientíficos considerou-se a ocorrência, ou não, de relação entre estes dois domínios do conhecimento. Foi também considerada, para as situações em que ocorre relação, a ocorrência, ou não, da predominância do conhecimento científico sobre o metacientífico. Para a análise da intradisciplinaridade entre diferentes conhecimentos científicos teve-se em consideração vários factores: a ocorrência ou não de relação; o nível de complexidade dos conhecimentos envolvidos (simples ou complexos); o tema a que se referem os conhecimentos (ao mesmo ou a temas diferentes); e a omissão de conhecimentos necessários para a compreensão das relações intradisciplinares. Neste instrumento, estipulou-se que o nível de complexidade dos conhecimentos envolvidos na relação assumia uma maior importância para o estabelecimento do grau de intradisciplinaridade do que o facto de esta ocorrer dentro do mesmo tema ou entre temas diferentes.

Segue-se um excerto de cada um dos instrumentos de caracterização do grau de intradisciplinaridade (Tabelas II e III) e unidades de análise classificadas de acordo com a escala destes instrumentos.

Tabela II - Excerto do instrumento de caracterização do grau de intradisciplinaridade entre conhecimentos científicos e metacientíficos

\begin{tabular}{|c|c|c|c|}
\hline $\mathrm{C}^{++}$ & $\mathrm{C}^{+}$ & $\mathrm{C}^{-}$ & $\mathrm{C}^{--}$ \\
\hline $\begin{array}{l}\text { Integram } \\
\text { apenas } \\
\text { conhecimentos } \\
\text { científicos } \\
\text { ou } \\
\text { Integram } \\
\text { apenas } \\
\text { conhecimentos } \\
\text { metacientíficos. }\end{array}$ & $\begin{array}{l}\text { Integram } \\
\text { conhecimentos } \\
\text { científicos e } \\
\text { metacientíficos, } \\
\text { mas sem os } \\
\text { relacionar. }\end{array}$ & $\begin{array}{l}\text { Integram } \\
\text { conhecimentos } \\
\text { científicos e } \\
\text { metacientíficos, } \\
\text { relacionando-os, } \\
\text { sendo conferido } \\
\text { maior estatuto } \\
\text { aos } \\
\text { conhecimentos } \\
\text { científicos. }\end{array}$ & $\begin{array}{l}\text { Integram } \\
\text { conhecimentos } \\
\text { científicos e } \\
\text { metacientíficos, } \\
\text { relacionando-os, } \\
\text { sendo conferido } \\
\text { a estes dois } \\
\text { tipos de } \\
\text { conhecimento } \\
\text { igual estatuto. }\end{array}$ \\
\hline
\end{tabular}




\section{Unidades de análise}

Geralmente os alimentos são misturas complexas de várias substâncias (Manual B. Secção Conhecimentos) - Grau C ${ }^{++}$.

Efectua uma pesquisa sobre o trabalho de alguns cientistas que contribuíram para o conhecimento da circulação sanguínea. Sugerimos-te, por exemplo, que te debruces sobre os trabalhos de William Harvey, procurando compreender algumas características da investigação científica (Manual B. Secção Orientações metodológicas) - Grau $\mathrm{C}^{--}$.

$\mathrm{Na}$ primeira unidade apenas estão presentes conhecimentos científicos (ausência de relação). Na segunda unidade de análise há uma sugestão de trabalho, que apela a um esbatimento das fronteiras entre os dois domínios do conhecimento, havendo referência à relação entre conhecimentos científicos e metacientíficos (dimensões filosófica e histórica), sendo conferido igual estatuto aos dois domínios de conhecimento.

Tabela III - Excerto do instrumento de caracterização do grau de intradisciplinaridade entre diferentes conhecimentos científicos

\begin{tabular}{|c|c|c|c|}
\hline $\mathrm{C}^{++}$ & $\mathrm{C}^{+}$ & $\mathrm{C}^{-}$ & $\mathrm{C}^{--}$ \\
\hline $\begin{array}{l}\text { Contemplam a } \\
\text { relação entre } \\
\text { conhecimentos de } \\
\text { ordem simples } \\
\text { dentro do mesmo } \\
\text { tema } \\
\text { ou } \\
\text { É omisso } \\
\text { conhecimento } \\
\text { científico } \\
\text { indispensável à } \\
\text { compreensão da } \\
\text { relação entre } \\
\text { conhecimentos } \\
\text { dentro do mesmo } \\
\text { tema } \\
\text { ou } \\
\text { Não é contemplada } \\
\text { a relação entre } \\
\text { conhecimentos } \\
\text { sendo estes } \\
\text { explorados de } \\
\text { forma isolada. }\end{array}$ & $\begin{array}{l}\text { Contemplam a } \\
\text { relação entre } \\
\text { conhecimentos de } \\
\text { ordem simples de } \\
\text { temas diferentes } \\
\text { ou } \\
\text { É omisso } \\
\text { conhecimento } \\
\text { científico } \\
\text { indispensável à } \\
\text { compreensão da } \\
\text { relação entre } \\
\text { conhecimentos de } \\
\text { temas diferentes. }\end{array}$ & $\begin{array}{l}\text { Contemplam a } \\
\text { relação entre } \\
\text { conhecimentos } \\
\text { de ordem } \\
\text { complexa, ou } \\
\text { entre estes e } \\
\text { conhecimentos } \\
\text { de ordem } \\
\text { simples, dentro } \\
\text { do mesmo tema. }\end{array}$ & $\begin{array}{l}\text { Contemplam a } \\
\text { relação entre } \\
\text { conhecimentos } \\
\text { de ordem } \\
\text { complexa, ou } \\
\text { entre estes e os } \\
\text { conhecimentos } \\
\text { de ordem } \\
\text { simples, de temas } \\
\text { diferentes. }\end{array}$ \\
\hline
\end{tabular}




\section{Unidades de análise}

Relacionar a estrutura e função dos diferentes vasos sanguíneos (Manual B. Secção Orientações metodológicas) - Grau $\mathrm{C}^{++}$.

Explicar o fenómeno de hematose pulmonar (Manual A. Secção Finalidades) Grau C'.

$\mathrm{Na}$ primeira unidade estão contempladas relações entre conhecimentos de ordem simples alusivos ao tema 'sistema circulatório'. Já na segunda unidade estão contempladas relações entre conhecimentos de ordem mais complexa, pertencentes ao tema 'sistema cárdio-respiratório'.

Como referido anteriormente, o estudo do nível de exigência conceptual fez-se com base no cálculo de um índice compósito que integrou os parâmetros: grau de complexidade de competências cognitivas científicas e de conhecimentos científicos e grau de intradisciplinaridade entre diferentes conhecimentos científicos ${ }^{8}$.

A análise do grau de complexidade de competências científicas foi feita com base na versão revista da taxonomia de objectivos educacionais de Bloom (Krathwohl, 2002), tendo-se considerado quatro níveis de complexidade das competências cognitivas científicas de acordo com os diferentes processos psicológicos envolvidos: competências simples de nível baixo; competências simples de nível elevado; competências complexas de nível baixo; e competências complexas de nível elevado. Com base nos quatro níveis de complexidade de competências científicas estabeleceu-se, para cada secção dos manuais, uma escala de quatro graus (G1, G2, G3 e G4) de complexidade crescente.

Segue-se um excerto do instrumento de caracterização do grau de complexidade das competências científicas (Tabela IV) e duas unidades de análise classificadas de acordo com a escala deste instrumento. 
Tabela IV - Excerto do instrumento de caracterização do grau de complexidade das competências cognitivas científicas

\begin{tabular}{llll}
\hline Grau 1 (CS) & Grau 2 (CS $\left.{ }^{+}\right)$ & Grau 3 (CC) & Grau 4 (CC (Com $^{+}$ \\
\hline Contemplam & Contemplam & Contemplam & Contemplam \\
competências & competências & competências & competências \\
com um baixo & com um nível & com um nível & com um nível \\
nível de & de & de & de \\
complexidade, & complexidade & complexidade & complexidade \\
envolvendo & superior ao & superior ao & muito \\
processos que & das CS, como & das CS, & elevado, tais \\
implicam a & a & envolvendo a & como as \\
mobilização de & compreensão & compreensão & capacidades \\
conhecimento & simples, ao & a um nível & de análise, \\
memorizado. & nível da & complexo e a & avaliação e \\
& exemplificação. & aplicação. & criação. \\
\hline
\end{tabular}

\section{Unidades de análise}

A circulação do sangue é assegurada pelas contracções do miocárdio (Manual B. Secção Conhecimentos) - Grau 1.

Informa-te das normas implementadas pelos poderes públicos, no sentido de reduzir o consumo do tabaco; verifica se essas normas são cumpridas nos meios que frequentas; faz uma pesquisa relativamente ao uso do tabaco na tua escola. Organiza os dados recolhidos e procura divulgá-los. Planeia uma campanha contra o consumo do tabaco que possa ser posta em prática junto da tua família, dos teus amigos e mesmo da tua escola (Manual B. Secção Orientações metodológicas) - Grau 4.

A primeira unidade de análise apela à memorização, isto é, a competências com um baixo nível de abstracção. Já a segunda unidade refere-se a uma actividade que envolve a mobilização de competências complexas, como a análise e a síntese.

A análise do grau de complexidade dos conhecimentos científicos teve em consideração diferentes ordens de complexidade dos conhecimentos, tal como definidos por Cantu e Herron (1978). Os conhecimentos podem ser classificados como sendo de ordem simples, envolvendo factos generalizados e conceitos de primeira ordem, e conhecimentos de ordem complexa, onde se incluem conceitos de segunda e terceira ordens. A categorização dos conceitos em várias ordens resulta de uma hierarquia estabelecida entre 
níveis de abstracção e de percepção. Com base nestes princípios estabeleceu-se uma escala de três graus (G1, G2 e G3) de complexidade crescente.

Segue-se um excerto do instrumento de caracterização do grau de complexidade dos conhecimentos científicos (Tabela V) e duas unidades de análise classificadas de acordo com a escala deste instrumento.

Tabela V - Excerto do instrumento de caracterização do grau de complexidade dos conhecimentos científicos

\begin{tabular}{|c|c|c|}
\hline Grau 1 & Grau 2 & Grau 3 \\
\hline $\begin{array}{l}\text { Os conhecimentos } \\
\text { científicos referem- } \\
\text { se a factos } \\
\text { generalizados } \\
\text { e/ou } \\
\text { a conceitos } \\
\text { simples, com um } \\
\text { baixo nível de } \\
\text { abstracção } \\
\text { (conceitos de } 1^{\text {a }} \\
\text { ordem). }\end{array}$ & $\begin{array}{l}\text { Os conhecimentos } \\
\text { científicos referem- } \\
\text { se a conceitos } \\
\text { complexos, com } \\
\text { um nível de } \\
\text { abstracção } \\
\text { superior ao dos } \\
\text { conceitos simples } \\
\text { e formados por } \\
\text { atributos } \\
\text { definidores não } \\
\text { perceptíveis } \\
\text { (conceitos de } 2^{\mathrm{a}} \\
\text { ordem). }\end{array}$ & $\begin{array}{l}\text { Os conhecimentos } \\
\text { científicos referem- } \\
\text { se a temas } \\
\text { unificadores, } \\
\text { envolvendo um } \\
\text { nível de } \\
\text { abstracção muito } \\
\text { elevado (conceitos } \\
\text { de } 3^{\mathrm{a}} \text { ordem). }\end{array}$ \\
\hline
\end{tabular}

\section{Unidades de análise}

Conhecer a constituição do sistema respiratório (Manual A. Secção Finalidades) - Grau 1.

Complementando conhecimentos adquiridos, pretende-se que a abordagem deste subtema conduza à compreensão integrada das interacções dos diferentes órgãos em funcionamento (Manual B. Secção Orientações metodológicas) - Grau 3.

Na primeira unidade são referidos conhecimentos com um baixo nível de abstracção. A segunda unidade faz referência a um tema integrador funcionamento do organismo como um todo - relativamente ao tópico "Organismo humano em equilíbrio". 
Para a análise dos critérios de avaliação, na relação autores de manuais escolares-professores, foram apenas consideradas as unidades de análise referentes a indicações para o professor, visto que é nesse espaço que se torna mais evidente o grau de explicitação dos autores dos manuais escolares relativamente à mensagem que pretendem transmitir. Nos instrumentos de análise foram considerados fundamentos teóricos sobre o significado dos critérios de avaliação em função do conceito de 'enquadramento' da teoria de Bernstein (1990). Com base nestes pressupostos teóricos, estabeleceu-se uma escala de quatro graus de enquadramento $\left(\mathrm{E}^{++}, \mathrm{E}^{+}, \mathrm{E}^{-}\right.$e $\left.\mathrm{E}^{--}\right)$e construíram-se descritivos relativos a cada secção dos manuais. Os valores fortes de enquadramento correspondem a uma clara explicitação do texto pretendido e os valores fracos traduzem-se numa fraca explicitação daquele.

$\mathrm{Na}$ análise do grau de explicitação do processo de construção da ciência, considerou-se a ocorrência de referência (mais ou menos genérica) a conhecimentos metacientíficos e a ocorrência da explicação dos conhecimentos no âmbito do ensino/aprendizagem da metaciência, ao nível do ensino das ciências ou na perspectiva do currículo.

$\mathrm{Na}$ análise do grau de explicitação das relações intradisciplinares, quer entre conhecimentos científicos e metacientíficos, quer entre diferentes conhecimentos científicos, teve-se em consideração a ocorrência de referência (mais ou menos genérica) às relações a estabelecer e a ocorrência da explicação (mais ou menos pormenorizada) do significado das relações a estabelecer.

Segue-se um excerto de cada um dos instrumentos de caracterização do grau de explicitação dos critérios de avaliação (Tabelas VI, VII e VIII) e unidades de análise classificadas de acordo com a escala destes instrumentos. Em nenhuma das unidades de análise foram atribuídos os graus mais elevados da escala de enquadramento, o que mostra, desde logo, um baixo nível de explicitação do texto veiculado nos manuais. 
Tabela VI - Excerto do instrumento de caracterização do grau de explicitação dos critérios de avaliação relativamente a conhecimentos de ordem simples (grau 2) relativos a dimensões da construção da ciência

\begin{tabular}{|c|c|c|c|}
\hline$E^{++}$ & $\mathrm{E}^{+}$ & $E^{-}$ & $\mathrm{E}^{-}$ \\
\hline $\begin{array}{l}\text { São especificados } \\
\text { conhecimentos de } \\
\text { ordem simples } \\
\text { relativos a } \\
\text { dimensões da } \\
\text { construção da } \\
\text { ciência. } \\
\text { É explicado o } \\
\text { significado desses } \\
\text { conhecimentos no } \\
\text { âmbito do } \\
\text { ensino/aprendizagem } \\
\text { da metaciência, } \\
\text { sendo também } \\
\text { referida a } \\
\text { importância destes } \\
\text { no ensino das } \\
\text { ciências, de acordo } \\
\text { com a perspectiva do } \\
\text { currículo. }\end{array}$ & $\begin{array}{l}\text { São especificados } \\
\text { conhecimentos de } \\
\text { ordem simples } \\
\text { relativos a } \\
\text { dimensões da } \\
\text { construção da } \\
\text { ciência. } \\
\text { É explicado o } \\
\text { significado desses } \\
\text { conhecimentos no } \\
\text { âmbito do } \\
\text { ensino/aprendizagem } \\
\text { da metaciência, } \\
\text { sendo também } \\
\text { referida a } \\
\text { importância destes } \\
\text { no ensino das } \\
\text { ciências em geral } \\
\text { (sem referir a } \\
\text { perspectiva de } \\
\text { ensino das ciências } \\
\text { que o currículo } \\
\text { defende). }\end{array}$ & $\begin{array}{l}\text { São } \\
\text { especificados } \\
\text { conhecimentos } \\
\text { de ordem } \\
\text { simples } \\
\text { relativos a } \\
\text { dimensões da } \\
\text { construção da } \\
\text { ciência, mas } \\
\text { não é } \\
\text { explicado o } \\
\text { significado } \\
\text { desses } \\
\text { conhecimentos } \\
\text { no âmbito da } \\
\text { aprendizagem } \\
\text { da } \\
\text { metaciência. }\end{array}$ & $\begin{array}{l}\text { São apenas } \\
\text { referidos, de } \\
\text { forma muito } \\
\text { genérica, } \\
\text { conhecimentos } \\
\text { de ordem } \\
\text { simples } \\
\text { relativos a } \\
\text { dimensões da } \\
\text { construção da } \\
\text { ciência. }\end{array}$ \\
\hline
\end{tabular}

\section{Unidade de análise}

Sugere-se a referência ao médico português Egas Moniz (29-11-1874 a 13-121955). Após cuidadoso estudo experimental, fez em 1927 a primeira angiografia cerebral no Homem. Dada a confiança no valor científico deste investigador, a sua iniciativa foi rapidamente aceite e praticada nas principais clínicas neurológicas e psiquiátricas do mundo. Em 1949 foi-lhe concedido o Prémio Nobel (Manual B. Secção Orientações metodológicas) - Grau E--.

Nesta unidade de análise estão contemplados conhecimentos de ordem simples relativos às dimensões filosófica, sociológica interna e externa, mas em que os conhecimentos são referidos de uma forma muito genérica. Em ambos os manuais não se registaram unidades atribuídas com o valor de enquadramento $\mathrm{E}^{-}$. 
Tabela VII - Excerto do instrumento de caracterização do grau de explicitação dos critérios de avaliação relativamente à intradisciplinaridade entre conhecimentos científicos e metacientíficos (graus $\mathrm{C}^{-}$e $\mathrm{C}^{--}$do instrumento da Tabela II)

\begin{tabular}{llll}
\hline $\mathbf{E}^{++}$ & $\mathbf{E}^{+}$ & $\mathbf{E}^{-}$ & $\mathbf{E}^{--}$ \\
\hline $\begin{array}{l}\text { São especificadas } \\
\text { as relações a }\end{array}$ & $\begin{array}{l}\text { São especificadas as } \\
\text { relações a }\end{array}$ & $\begin{array}{l}\text { São especificadas } \\
\text { as relações a }\end{array}$ & $\begin{array}{l}\text { São apenas } \\
\text { referidas, de forma }\end{array}$ \\
$\begin{array}{l}\text { estabelecer entre } \\
\text { conhecimentos }\end{array}$ & $\begin{array}{l}\text { conhecimentos } \\
\text { científicos e }\end{array}$ & $\begin{array}{l}\text { conhecimentos } \\
\text { científicos e }\end{array}$ & $\begin{array}{l}\text { relações a } \\
\text { estabelecer entre }\end{array}$ \\
conhecicos e & conhecimentos & conhecimentos & conhecimentos \\
metacientíficos, & metacientíficos, & metacientíficos, não & científicos e \\
sendo explicado, de & sendo explicado, & sendo explicado o & conhecimentos \\
forma & apenas de forma & seu significado no & metacientíficos. \\
pormenorizada, o & geral, o seu & âmbito do ensino & \\
seu significado no & significado no âmbito & das ciências. & \\
âmbito do ensino & do ensino das & & \\
das ciências. & ciências. & & \\
\hline
\end{tabular}

\section{Unidades de análise}

Sugere-se a referência ao médico português Egas Moniz (29-11-1874 a 13-121955). Após cuidadoso estudo experimental, fez em 1927 a primeira angiografia cerebral no Homem. Dada a confiança no valor científico deste investigador, a sua iniciativa foi rapidamente aceite e praticada nas principais clínicas neurológicas e psiquiátricas do mundo. Em 1949 foi-lhe concedido o Prémio Nobel (Manual B. Secção Orientações metodológicas) - Grau E-.

Devem ser privilegiadas as doenças e as técnicas sobre as quais os alunos demonstraram maior curiosidade durante a abordagem dos sistemas (Manual A. Secção Orientações metodológicas) - Grau E--.

$\mathrm{Na}$ primeira unidade de análise, é estabelecida a relação entre conhecimentos científicos (técnicas de observação do sistema nervoso) e metacientíficos (dimensões filosófica, sociológica interna e externa), mas em que essa relação não é explicada. Na segunda unidade de análise, a relação entre os conhecimentos científico e o metacientífico, na vertente TecnologiaSociedade (dimensão sociológica externa), é referida de forma muito genérica. 


\section{Tabela VIII - Excerto do instrumento de caracterização do grau de explicitação dos critérios de avaliação relativamente à intradisciplinaridade entre diferentes conhecimentos científicos (grau $\mathrm{C}^{-}$da Tabela (II)}

\begin{tabular}{|c|c|c|c|}
\hline$E^{++}$ & $\mathrm{E}^{+}$ & $E^{-}$ & $E^{--}$ \\
\hline $\begin{array}{l}\text { São } \\
\text { especificadas } \\
\text { relações a } \\
\text { estabelecer } \\
\text { entre } \\
\text { conhecimentos } \\
\text { de ordem } \\
\text { complexa, ou } \\
\text { entre estes e } \\
\text { conhecimentos } \\
\text { de ordem } \\
\text { simples, dentro } \\
\text { do mesmo } \\
\text { tema, sendo } \\
\text { explicado, de } \\
\text { forma } \\
\text { pormenorizada, } \\
\text { o seu } \\
\text { significado na } \\
\text { construção de } \\
\text { temas } \\
\text { unificadores. }\end{array}$ & $\begin{array}{l}\text { São } \\
\text { especificadas } \\
\text { relações a } \\
\text { estabelecer } \\
\text { entre } \\
\text { conhecimentos } \\
\text { de ordem } \\
\text { complexa, ou } \\
\text { entre estes e } \\
\text { conhecimentos } \\
\text { de ordem } \\
\text { simples, dentro } \\
\text { do mesmo tema, } \\
\text { sendo explicado, } \\
\text { apenas de forma } \\
\text { geral, o seu } \\
\text { significado na } \\
\text { construção de } \\
\text { temas } \\
\text { unificadores. }\end{array}$ & $\begin{array}{l}\text { São } \\
\text { especificadas } \\
\text { relações a } \\
\text { estabelecer } \\
\text { entre } \\
\text { conhecimentos } \\
\text { de ordem } \\
\text { complexa, ou } \\
\text { entre estes e } \\
\text { conhecimentos } \\
\text { de ordem } \\
\text { simples, dentro } \\
\text { do mesmo tema, } \\
\text { não sendo } \\
\text { explicado o seu } \\
\text { significado na } \\
\text { construção de } \\
\text { temas } \\
\text { unificadores. }\end{array}$ & $\begin{array}{l}\text { São apenas } \\
\text { referidas, de } \\
\text { forma muito } \\
\text { genérica, } \\
\text { relações a } \\
\text { estabelecer entre } \\
\text { conhecimentos } \\
\text { de ordem } \\
\text { complexa, ou } \\
\text { entre estes e } \\
\text { conhecimentos } \\
\text { de ordem } \\
\text { simples, dentro } \\
\text { do mesmo tema. }\end{array}$ \\
\hline
\end{tabular}

\section{Unidades de análise}

Nesta altura, pode mais uma vez explorar com os alunos a função das válvulas do coração, salientando o papel que estas têm no percurso unidireccional da circulação do sangue. Deve alertar para os perigos que estão associados ao mau funcionamento destas, tais como o retrocesso do sangue, o que leva a uma sobrecarga do fluxo sanguíneo nas zonas anteriores à lesão, acompanhado, geralmente, por um défice às zonas posteriores da lesão (necrose celular) (Manual A. Secção Conhecimentos) - Grau E'.

Consideramos que o conceito de enzima é fundamental para a relação que os alunos devem estabelecer entre a função do sistema digestivo e o fenómeno da digestão (Manual A. Secção Conhecimentos) - Grau E--.

Na primeira unidade de análise, é especificada a relação a estabelecer entre conhecimentos de ordem complexa e entre estes e conhecimentos de 
ordem simples, em termos da estrutura e funcionamento do órgão coração. $\mathrm{Na}$ segunda unidade de análise, apesar da referência ao conceito de enzima, há apenas uma menção à relação a estabelecer entre o sistema digestivo e o fenómeno da digestão.

\section{Apresentação e análise dos resultados}

\section{Processo de construção da ciência}

Os resultados da análise das dimensões do processo de construção da ciência presentes nos dois manuais escolares em estudo (MA, MB) encontramse expressos na Figura 2, a par dos resultados da análise dessas dimensões nos documentos curriculares (CE, OC). Para cada dimensão, calculou-se a frequência de excertos analisados (expressa em percentagem relativa) de acordo com a escala de quatro graus dos respectivos instrumentos.

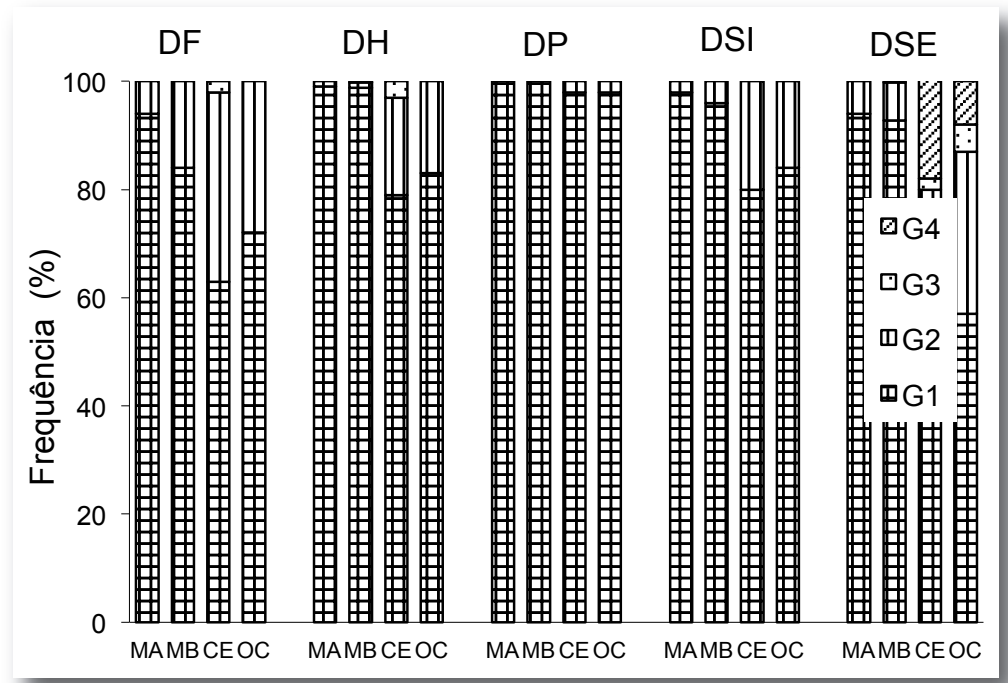

Figura 2 - Processos de recontextualização entre a mensagem dos manuais (MA e MB) e a mensagem do currículo (CE e OC) relativamente ao processo de construção da ciência (DF - dimensão filosófica; DH dimensão histórica; DP - dimensão psicológica; DSI - dimensão sociológica interna; DSE - dimensão sociológica externa) 
Constata-se que em ambos os manuais escolares o processo de construção da ciência não é valorizado. De facto, quando se consideraram todas as referências ao domínio metacientífico, independentemente da dimensão, verificou-se que $94 \%$ do texto do manual A e $84 \%$ do manual B não mencionam nem conhecimentos, nem competências metacientíficos.

Não ocorre, em qualquer dos manuais, alusão à dimensão psicológica da construção da ciência e a abordagem às dimensões histórica e sociológica interna é muito pouco expressiva. As dimensões filosófica e sociológica externa são as mais focadas e, mesmo assim, numa diminuta percentagem ao nível do grau 2, o que significa que elas são abordadas em termos das competências que Ihes estão associadas ou de conhecimentos de ordem simples. Estas competências são indicadas, sobretudo, ao nível das actividades de aprendizagem, referindo-se, maioritariamente, a capacidades de observação e interpretação de dados experimentais e de interpretação de representações gráficas. A dimensão sociológica externa é explorada sobretudo ao nível dos conhecimentos de ordem simples, os quais focam, maioritariamente, a relação entre os avanços tecnológicos e os diagnósticos de doenças e avaliação da condição física, explorando de uma forma mais directa a relação entre a tecnologia e a sociedade. Comparativamente, o manual B apresenta uma maior expressão da metaciência, com mais referências a competências metacientíficas referentes à dimensão filosófica. No entanto, essas competências não são explicitamente relacionadas com a construção da ciência, não havendo assim um contributo para a compreensão desta. Em termos dos processos de recontextualização, que têm lugar na passagem dos documentos curriculares para os manuais escolares, os resultados mostram que eles se traduzem, em geral, numa diminuição acentuada do grau de expressão da construção da ciência nos manuais. Este facto é particularmente evidente ao nível da dimensão sociológica externa, nomeadamente quando se compara a mensagem dos manuais com a mensagem expressa no documento Competências Essenciais.

\section{Intradisciplinaridade entre os conhecimentos científico e metacientífico e entre diferentes conhecimentos científicos}

A Figura 3 expressa os resultados obtidos na análise da intradisciplinaridade entre conhecimentos científicos e metacientíficos (Intra 
C-M) e entre diferentes conhecimentos científicos (Intra C-C), ao nível dos manuais (MA, MB) e dos documentos curriculares (CE, OC).

Intra C-M

Intra C-C

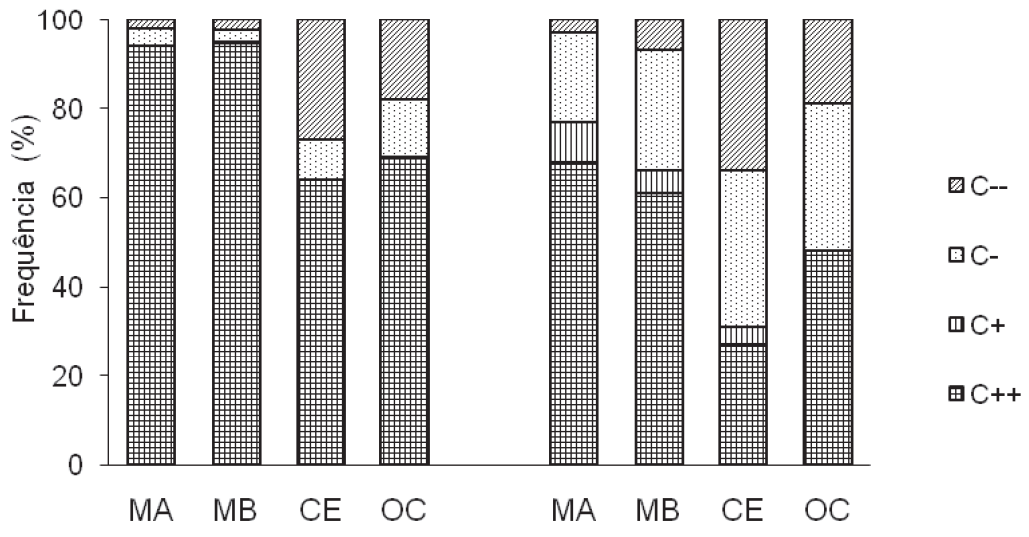

Figura 3 - Intradisciplinaridade entre conhecimentos científicos e metacientíficos (Intra C-M) e entre diferentes conhecimentos científicos (Intra C-C) nos manuais escolares (MA e MB) e nos documentos curriculares (CE e OC)

No que concerne à análise da intradisciplinaridade entre conhecimentos científicos e metacientíficos, é visível, em ambos os manuais, uma elevada percentagem do texto que refere apenas conhecimento científico sem qualquer relação com o conhecimento metacientífico (grau C++): $94 \%$ do texto no manual A e $94.5 \%$ no manual B. Verifica-se, assim, que em ambos os manuais predominam valores fortes de classificação que se traduzem em fronteiras bem definidas entre conhecimento científico e metacientífico. No entanto, observa-se que, quando ocorre relação entre estes dois domínios do conhecimento, prevalece o grau de intradisciplinaridade em que o conhecimento científico assume maior estatuto (grau C-), ou seja, a situação considerada mais favorável para o ensino das ciências. No manual A é na secção conhecimentos que prevalecem relações dessa natureza e no manual B é na secção orientações metodológicas. 
Em termos dos processos de recontextualização, é visível que estes se traduzem numa diminuição de referências a relações intradisciplinares entre conhecimento científico e metacientífico ao nível da mensagem dos manuais, sendo que os documentos curriculares já veiculam uma mensagem com uma baixa referência ao estabelecimento de relações a este nível.

A análise da intradisciplinaridade entre diferentes conhecimentos científicos revela que em ambos os manuais, principalmente no manual A, prevalecem valores fortes de classificação $(77 \%$ dos graus $\mathrm{C}++$ e $\mathrm{C}+$ no manual A e $66 \%$ no manual B), ou seja, dominam as relações entre conhecimentos de ordem simples. Cálculos efectuados a partir dos dados recolhidos mostram que uma percentagem considerável de indicações nem sequer contempla a intradisciplinaridade entre diferentes conhecimentos científicos (32\% no manual A e $28 \%$ no manual B). Contudo, destaca-se o manual $\mathrm{B}$ por ser aquele que mais fomenta o estabelecimento de relações entre conhecimentos científicos de ordem complexa (graus C- e C--), contribuindo, de alguma forma, para uma compreensão mais abrangente dos conhecimentos científicos. Quando se considera a análise ao nível das secções, constata-se que, em termos dos objectivos de aprendizagem, o manual $\mathrm{A}$ dá algum destaque às relações entre conhecimentos de ordem complexa (36\% do grau C- ao nível das finalidades); no entanto, estas finalidades não se traduzem nos conhecimentos explorados, nas actividades de aprendizagem propostas e nas actividades de avaliação, pois a este nível predominam relações entre conhecimentos de ordem simples, aqueles que, conceptualmente, envolvem um menor número de relações, sendo por isso menos abrangentes. No manual B é a secção avaliação que foca uma maior intradisciplinaridade entre conhecimentos complexos (48\% graus C- e C--).

Quanto aos processos de recontextualização, constata-se que estes se expressam numa mensagem dos manuais escolares menos eficiente na articulação de ideias e, por conseguinte, menos eficiente na promoção de uma compreensão mais abrangente da ciência, já que ambos os manuais apresentam uma menor referência à relação entre conhecimentos de ordem complexa (graus $\mathrm{C}^{-}$e $\mathrm{C}^{--}$) comparativamente com os documentos curriculares. A transformação da mensagem torna-se mais evidente entre as Competências Essenciais e o manual A. 
$\mathrm{Na}$ análise da intradisciplinaridade entre diferentes conhecimentos científicos, importa salientar as considerações que se tomaram relativamente à ausência de conhecimentos considerados necessários para o estabelecimento de relações entre conhecimentos científicos e a compreensão de conceitos mais abrangentes. Assim, considerou-se que para as aprendizagens, de final do $3^{\circ}$ Ciclo do Ensino Básico, do tópico "Organismo humano em equilíbrio", seria relevante explicitar a importância da compreensão de que o organismo tem a capacidade de, dentro de certos limites, regular o seu meio interno - conceito de homeostasia (exemplos como a variação da temperatura em determinadas situações poderiam ser apresentados). Indicações desta natureza contribuiriam para um entendimento mais abrangente das relações que se estabelecem entre os vários sistemas do organismo e orientariam as aprendizagens dos alunos.

\section{Nível de exigência conceptual}

No estudo do nível de exigência conceptual, foi calculado o índice compósito com base em três parâmetros: intradisciplinaridade entre diferentes conhecimentos científicos, grau de complexidade de competências cognitivas e grau de complexidade de conhecimentos científicos. Na Figura 4 apresentam-se os resultados referentes à análise do grau de complexidade das competências e dos conhecimentos científicos ao nível dos manuais e dos documentos oficiais (a análise da intradisicplinaridade foi discutida anteriormente, com base na Figura 3).

Os resultados apresentados na Figura 4 revelam que nos manuais predominam competências de grau de complexidade baixo (G1 e G2 - 80\% no manual A e $69 \%$ no manual B) e referências a factos generalizados e conceitos simples de $1^{\mathrm{a}}$ ordem (G1) - 73.9\% no manual A e $62 \%$ no manual B. Chega-se mesmo a verificar que, em termos de conhecimentos científicos, nos manuais escolares, não são praticamente referidos temas integradores, constatando-se uma acentuada lacuna ao nível dos conceitos mais abrangentes que unificam e consolidam as aprendizagens realizadas. Ora, tratando-se do último ano de escolaridade do ensino básico, seria de esperar um nível de conceptualização das aprendizagens mais elevado, já que o tema organizador "Viver melhor na Terra" "constitui o culminar do desenvolvimento das aprendizagens anteriores e tem como finalidade capacitar o aluno para a 
importância da sua intervenção individual e colectiva no equilíbrio da Terra (...)" (DEB, 2001, p. 146).

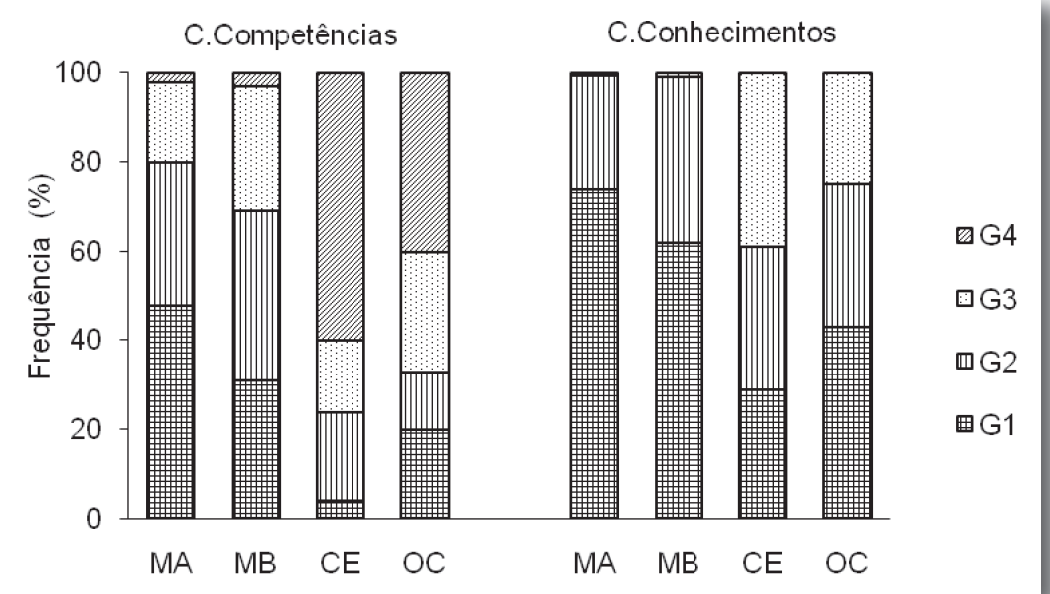

Figura 4 - Grau de complexidade das competências cognitivas e dos conhecimentos científicos* nos manuais escolares (MA e MB) e nos documentos curriculares (CE e OC)

* A escala usada na análise do grau de complexidade dos conhecimentos científicos apenas contempla três graus (G1, G2 e G3).

No que concerne aos processos de recontextualização que transformam a mensagem dos manuais a partir da mensagem dos documentos oficiais, constata-se que estes ocorrem no sentido de uma diminuição das referências que contemplam competências e conceitos com um grau de complexidade alto. Verifica-se ainda que o grau de recontextualização é maior entre as mensagens do manual A e do documento Competências Essenciais.

Através do cálculo do índice compósito (com base nos três parâmetros atrás mencionados) obteve-se o nível de exigência conceptual veiculado nos manuais e nos documentos oficiais (Figura 5). 


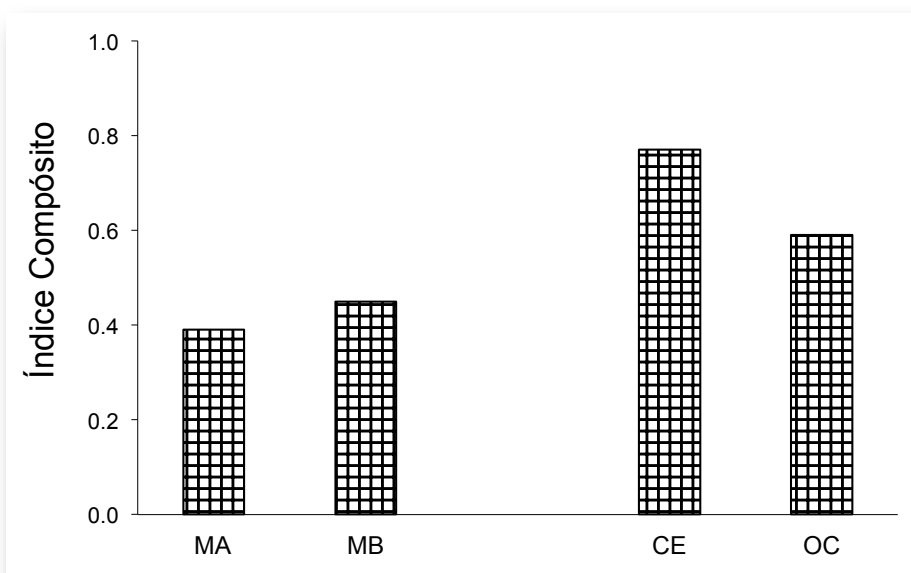

Figura 5 - Processos de recontextualização ao nível da mensagem dos manuais (MA e MB) relativamente à mensagem do currículo (CE e OC), quanto ao nível de exigência conceptual no domínio científico

A partir do cálculo do índice compósito registou-se um valor de 0.39 no manual A e 0.45 no manual B. São valores baixos, indicativos de uma mensagem que orienta o contexto de transmissão/aquisição para um grau de conceptualização baixo, sobretudo a mensagem do manual A. Como seria de esperar, face à análise efectuada aos parâmetros usados no cálculo do índice compósito, os processos de recontextualização que ocorrem entre os documentos curriculares e os manuais escolares traduzem alterações bastante evidentes nestes últimos, conduzindo a uma diminuição da conceptualização das aprendizagens, a qual é mais acentuada entre a mensagem das Competências Essenciais e a do manual A. Com efeito, embora os dois manuais promovam, principalmente, a memorização (MA) e a compreensão a um nível simples (MB), o manual $B$ é o que mais fomenta o desenvolvimento de competências complexas. Por outro lado, o manual $B$ contempla mais conhecimentos de ordem complexa (38\% de G2 e G3) do que o manual A (26.1\% de G2 e G3). Como tal, o nível de exigência conceptual é ligeiramente maior no manual $\mathrm{B}$. 


\section{Critérios de avaliação}

A análise do grau de explicitação da mensagem dos manuais escolares incidiu apenas sobre as indicações, para o professor, referentes ao processo de construção da ciência e às relações intradisciplinares a estabelecer entre conhecimentos científicos e metacientíficos e entre diferentes conhecimentos científicos. No entanto, constatou-se um número muito reduzido de unidades para a análise pretendida (e.g. apenas 14 unidades de análise referentes a indicações para o professor mencionam conhecimentos metacientíficos), tornando-a pouco significativa. Paralelamente, verificou-se que todas as indicações para o professor referentes a conhecimentos metacientíficos e à intradisciplinaridade entre conhecimentos científicos e metacientíficos e entre diferentes conhecimentos científicos não são explícitas - apenas têm expressão os graus mais fracos da escala de enquadramento ( $\mathrm{E}^{--}$e $\left.\mathrm{E}^{-}\right)$.

Ao proceder-se à análise dos critérios de avaliação dos mesmos parâmetros ao nível dos documentos oficiais, verificou-se que, também naquele contexto, a análise estava confinada a um baixo número de unidades de análise e que a mensagem dos documentos oficiais é pouco explícita nos parâmetros em causa. Perante este resultado, coloca-se a hipótese de a fraca explicitação das aprendizagens, que se verifica ao nível dos documentos curriculares, constituir uma razão para a fraca explicitação dessas aprendizagens ao nível de manuais escolares. Estes resultados sugerem que a recontextualização da mensagem dos documentos curriculares para os manuais escolares pode depender do grau de explicitação da mensagem daqueles.

\section{Conclusões}

Este estudo incidiu sobre a análise do discurso pedagógico veiculado em dois manuais escolares de Ciências Naturais do $3^{\circ}$ Ciclo do Ensino Básico, referentes ao tema organizador "Viver melhor na Terra", tendo como foco quatro características pedagógicas centrais no ensino das ciências: processo de construção da ciência; relações intradisciplinares; nível de exigência conceptual; e critérios de avaliação. Pretendeu-se também caracterizar os processos de recontextualização que ocorrem na mensagem 
do currículo quando esta é traduzida na mensagem dos manuais escolares, tendo-se, para tal, procedido, num estudo mais amplo, a uma análise da mensagem dos documentos curriculares Competências Essenciais e Orientações Curriculares relativamente àquelas características pedagógicas (Calado, 2007).

Em termos de relevância desta investigação, salientam-se dois aspectos: 1) o contributo para o corpo de resultados da investigação educacional no domínio da análise curricular baseados num modelo teórico com uma forte estrutura conceptual e um forte poder explicativo - o modelo do discurso pedagógico de Bernstein (1990, 2000); e 2) a caracterização das (des)continuidades entre as intenções sobre a aprendizagem científica veiculadas em documentos curriculares e o modo como essas são expressas em manuais escolares. Com efeito, os resultados vão ao encontro de outros obtidos em estudos anteriores (e.g. Santos, 2001; Knain, 2001) que apontam para o facto de existir, nos manuais, uma discrepância entre a imagem escolar da ciência e o mundo da ciência real, de estes continuarem a valorizar um ensino transmissivo, contendo textos pouco reflexivos, focando-se nos produtos da ciência e privilegiando o conhecimento factual. Esta tendência poderá reflectir a dificuldade dos autores dos manuais em traduzir os princípios gerais para o contexto mais específico dos manuais escolares.

No que concerne ao primeiro objectivo proposto neste estudo "analisar a mensagem de manuais escolares relativamente às quatro características pedagógicas seleccionada" -, verificou-se que a mensagem dos manuais escolares analisados praticamente não valoriza o processo de construção da ciência, nem a relação entre o conhecimento científico e a forma como este é 'construído' (conhecimento metacientífico). De facto, praticamente só as dimensões filosófica e sociológica externa apresentam expressão ao nível dos manuais. Acresce o facto de as referências a metodologias científicas e à relação C-T-S (Ciência, Tecnologia e Sociedade) se basearem, principalmente, em competências associadas a estas dimensões, sem que seja estabelecida uma ligação com a construção da ciência, ou sem se explorarem conhecimentos com um grau de complexidade elevado. Este resultado revela um afastamento entre a mensagem dos manuais analisados e um dos actuais objectivos centrais no ensino das ciências: a compreensão de como se constrói o conhecimento científico. 
O estudo também revelou um baixo grau de intradisciplinaridade entre diferentes conhecimentos científicos, condição que favorece o predomínio de conceitos científicos menos abrangentes e que envolvem menos relações entre diferentes conceitos, em detrimento do foco em temas integradores.

Em ambos os manuais ocorre um maior enfoque em competências cognitivas de grau simples, destacando-se a memorização e a compreensão a um nível simples. Mais ainda, constatou-se que é ao nível do manual mais seleccionado pelos professores que ocorre uma menor incidência em competências cognitivas complexas.

Face ao maior enfoque em competências e conhecimentos de ordem simples e ao insuficiente estabelecimento de relações intradisciplinares, pode afirmar-se que o nível de conceptualização das aprendizagens, tal como expresso na mensagem dos manuais analisados, é baixo.

Quanto ao objectivo "caracterizar a extensão e o sentido da recontextualização presente nos manuais escolares em relação aos documentos curriculares", constata-se que os manuais analisados incorporam um elevado grau de recontextualização das mensagens dos documentos oficiais Competências Essenciais e Orientações Curriculares, sobretudo das Competências Essenciais, no sentido de uma menor expressão e menor conceptualização das características pedagógicas em análise. Constatou-se também que, de um modo geral, a mensagem de um dos manuais - o mais seleccionado no ano escolar 2004/05 - é mais distante da mensagem dos documentos curriculares do que a mensagem do outro manual, traduzindo, assim, um grau de recontextualização mais elevado.

Dado que em análises comparativas dos dois documentos curriculares, quanto aos temas organizadores "Viver melhor na Terra" (Alves, 2007; Calado, 2007) e "Sustentabilidade na Terra" (Ferreira, 2007; Ferreira \& Morais, 2010), se verificaram processos de recontextualização também traduzidos numa diminuição da expressão e da conceptualização das características em estudo, pode-se deduzir que a tendência encontrada é a ocorrência de um decréscimo da expressão e do grau de conceptualização dessas características quando um texto é transferido de um contexto para outro. Mais ainda, é de salientar que, nesses estudos, se constatou que a mensagem dos documentos curriculares já traduz um grau de conceptualização consideravelmente baixo em ambos os temas organizadores. 
Uma possível hipótese para explicar esta tendência pode estar relacionada com o baixo grau de explicitação das aprendizagens observado nos documentos curriculares analisados. Com efeito, os estudos anteriormente citados (Alves, 2007; Calado, 2007; Ferreira, 2007) verificaram que os documentos curriculares são pouco explícitos relativamente ao processo de construção da ciência e à intradisciplinaridade entre conhecimentos científicos e metacientíficos e entre diferentes conhecimentos científicos. Tal significa que os documentos curriculares, sobretudo as Orientações Curriculares, não explicitam o texto que valorizam, permitindo um maior controlo aos autores dos manuais escolares e professores na abordagem do domínio metacientífico e no estabelecimento de relações intradisciplinares.

Verifica-se, com o presente estudo, que este maior controlo resultou, nos manuais escolares, num baixo grau de expressão do processo da construção da ciência e num baixo grau de intradisciplinaridade que, consequentemente, contribui para um baixo nível de conceptualização das aprendizagens (maioritariamente, ao nível do manual mais seleccionado). É interessante verificar que esta tendência foi também constatada por um outro estudo (Alves, 2007), que procedeu à análise das mesmas características pedagógicas que constituem o foco do presente estudo, em software didáctico relativo ao ensino das ciências.

Relativamente ao último objectivo do estudo - "reflectir sobre as consequências da recontextualização do discurso pedagógico na aprendizagem científica de todos os alunos em contexto de flexibilidade curricular" -, os resultados encontrados assumem relevância quando se considera que os autores de manuais escolares recorrem, sobretudo, às orientações específicas da disciplina (Orientações Curriculares) para elaborarem os textos dos manuais e que os professores têm como prática orientar o processo de ensino-aprendizagem pelos manuais escolares (Neves \& Morais, 2006). Ora, os resultados sugerem uma relação entre o grau de explicitação das aprendizagens e o sentido dos processos de recontextualização entre os vários documentos e, se se verificou que estes ocorrem no sentido de uma menor expressão e conceptualização do processo de construção da ciência, da intradisciplinaridade, das competências e dos conhecimentos científicos, é legítimo problematizar a inclusão dessas 
características no ensino das ciências. Com efeito, num contexto de flexibilidade curricular, os autores de manuais escolares e os professores, sobretudo os que revelam lacunas ao nível de formação científica e pedagógica, poderão não ser capazes de 'construir' um currículo que tenha em consideração os resultados de investigação sobre a importância de determinadas características pedagógicas na aprendizagem dos alunos. Tal como Neves e Morais (2006) referem:

Uma compreensão distinta dos professores/escolas (e dos autores de manuais escolares) do que significa uma aprendizagem eficiente, em termos das especificidades dos alunos, escolas e seus contextos geográficos, pode restringir, num contexto de flexibilidade curricular, o sucesso da reforma no que diz respeito ao sucesso de todos os alunos (p. 17).

Por outro lado, quando os professores adequam o currículo que 'constroem' às especificidades dos alunos e escolas poderão promover um processo de ensino/aprendizagem com diferentes níveis de exigência conceptual, ficando comprometido o sucesso de uma alfabetização científica de nível elevado para todos os alunos. De facto, verifica-se que os professores tendem a variar o nível de exigência conceptual do contexto de ensino/aprendizagem de acordo com o contexto social onde se inserem, contribuindo, deste modo, para aumentar o fosso entre alunos de origens sócioeconómicas diferentes relativamente à alfabetização científica (Morais, 1991).

Face ao exposto, consideram-se necessários, nos manuais escolares (e no currículo), critérios de avaliação explícitos pelo menos ao nível dos conhecimentos e competências a serem desenvolvidos e da articulação conceptual entre conhecimentos (intradisciplinaridade), para que os professores promovam uma aprendizagem científica eficiente. De acordo com Neves e Morais (2006):

[para que] a qualidade de educação exista para todos os alunos, tornar o currículo flexível não significa deixar para professores/escolas (e autores de manuais escolares) a selecção dos conceitos, competências e objectivos a serem desenvolvidos mas a selecção, em termos de especificidades dos alunos, de actividades que permitam que todos eles tenham acesso aos mesmos conceitos e a competências de níveis semelhantes de complexidade (p. 17).

Este estudo realça a importância do papel que os autores de manuais escolares (e os professores) podem desempenhar no grau e sentido da 
recontextualização da mensagem pedagógica contida nos documentos curriculares oficiais. Com a maior autonomia de que dispõem, os autores de manuais (e os professores) poderão recontextualizar a mensagem dos documentos curriculares (e dos manuais) no sentido de veicular uma mensagem que promova uma compreensão mais aprofundada de conhecimentos relacionados com a construção da ciência e sua relação com os conhecimentos científicos. Neste sentido, o estudo aponta para a importância da formação de professores, para que a maior autonomia de que dispõem lhes permita uma recontextualização dos princípios orientadores dos documentos curriculares e manuais escolares, de modo a que todos os alunos tenham acesso a uma educação que promova uma alfabetização científica de nível elevado.

A importância da formação de professores assume outra relevância quando pensamos que a equipa de autores de manuais escolares é constituída, também, por professores, funcionando estes como agentes que operacionalizam os processos de recontextualização ao nível do campo de recontextualização pedagógica.

Ainda no âmbito da formação de professores, há um último aspecto que importa mencionar e que se prende com o facto de os manuais analisados neste estudo terem sido os mais seleccionados pelos professores no ano escolar em que a actual reorganização curricular entrou em vigor (2004/05). Dado o facto de se verificar uma preferência diferencial dos professores pelos manuais disponíveis no mercado e de a prática pedagógica a que estes podem induzir ter implicações na socialização dos alunos, tornase "crucial que o professor tome consciência do espaço de autonomia que ele pode ter na selecção dos livros" (Neves, 1991, p. 96) e na transformação da mensagem que estes veiculam (particularmente da mensagem dos manuais alvo deste estudo). Castro e Cachapuz (2005) destacam o papel do professor na articulação manual-aluno e reforçam a necessidade de formação (inicial e contínua) dos professores no que concerne à selecção e utilização deste material curricular. Mais, acrescentam que uma boa utilização do manual escolar passa por encará-lo como uma fonte de sugestões ou de consulta, sendo uma das estratégias de sala de aula possíveis, entre tantas outras. 


\section{Agradecimentos} do estudo.

As autoras agradecem à Fundação para a Ciência e Tecnologia o financiamento

Agradecem também à Professora Ana Maria Morais as sugestões e críticas feitas durante a realização do projecto em que este estudo se insere.

\section{Notas}

1 O discurso pedagógico oficial, do modelo do discurso pedagógico de Bernstein (1990, 2000), corresponde ao currículo formal referido por vários autores (e.g. Pacheco, 2001). O discurso pedagógico de reprodução daquele modelo corresponde ao currículo apresentado (Gimeno, 1988, citado em Pacheco, 2001).

2 Segundo Bernstein (1999), o conhecimento científico apresenta uma estrutura hierárquica que está orientada no sentido de integrar proposições para operar em níveis de abstracção crescentes, em que o desenvolvimento de uma teoria ocorre no sentido de formular uma outra teoria mais geral e mais integradora do que a prévia.

3 Ano escolar em que a actual reorganização curricular alcançou o $9^{\circ}$ ano de escolaridade.

4 Foram tomadas algumas considerações de acordo com a realidade do texto em análise, nomeadamente o facto de uma actividade de aprendizagem constituir uma U.A., enquanto nas actividades de avaliação, que são extensas, considerou-se uma questão e respectivas alíneas (quando houvessem) uma U.A. No MA totalizaram 652 U.A. e no MB. 419 U.A.

5 Ver instrumentos em Calado (2007). Também disponível online em http://essa.fc.ul.pt/materiais_instrumentos_texto.htm.

6 Sobre a análise do discurso pedagógico oficial (DPO) veiculado nos documentos curriculares ver Alves (2007), Calado (2007) e Ferreira (2007), que analisam as características pedagógicas em foco neste artigo ao nível dos dois documentos curriculares, nos temas organizadores "Viver melhor na Terra" e "Sustentabilidade na Terra".

7. Neste instrumento, importa salientar as considerações que foram tomadas em relação ao grau 2. Como os dados empíricos revelaram que as competências metacientíficas são, muitas vezes, exploradas sem estar prevista a sua relação com a construção da ciência - não se promove a compreensão da natureza da ciência -, foi necessário fazer a distinção entre as competências metacientíficas que efectivamente estão relacionadas e as que não estão. Assim, o descritivo do grau 2 engloba as três situações relatadas no excerto do instrumento.

8. Equação global do índice compósito baseado nos três parâmetros - grau de intradisciplinaridade entre diferentes conhecimentos científicos (IntraCC), grau de complexidade de competências científicas (CComp) e grau de complexidade de conhecimentos científicos (CConh): 


\section{Referências}

Alves (2007). O currículo, o software didáctico e a prática pedagógica: Análise sociológica de textos e contextos do ensino das ciências (Tese de mestrado). Lisboa: Universidade Católica de Portugal - Faculdade de Educação e Psicologia.

Bernstein, B. (1990). Class, codes and control: Volume IV, The structuring of pedagogic discourse. Londres: Routledge.

Bernstein, B. (1999). Vertical and horizontal discourses: An essay. British Journal of Sociology of Education, 20(2), 157-173.

Bernstein, B. (2000). Pedagogy, symbolic control and identity: Theory, research, critique. Londres: Rowman \& Littlefield.

Calado, S. (2007). Currículo e manuais escolares - Processos de recontextualização no discurso pedagógico de Ciências Naturais do $3^{\circ}$ Ciclo do Ensino Básico (Tese de mestrado). Lisboa: Universidade de Lisboa - Departamento de Educação da Faculdade de Ciências.

Cantu, L., \& Herron, J. (1978). Concrete and formal Piagetian stages and science concept attainment. Journal of Research in Science Teaching, 15(2), 135-143.

Castro, C., \& Cachapuz, A. (2005). Os manuais escolares na formação inicial de professores de Ciências Naturais. In I. Alarcão, A. Cachapuz, T. Medeiros \& M. Jesus (Orgs.), Supervisão: Investigação em contexto educativo (pp. 263-290). Aveiro: Universidade de Aveiro.

Castro, S. (2006). A construção da Ciência na educação científica do Ensino Secundário - Análise do novo programa de Biologia e Geologia do $10^{\circ}$ ano (Tese de mestrado). Lisboa: Universidade de Lisboa - Faculdade de Ciências.

Decreto-Lei n. ${ }^{\circ}$ 6/2001, de 18 de Janeiro.

Departamento de Educação Básica (DEB) (1999). Gestão flexível do currículo. Lisboa: Ministério da Educação.

Departamento de Educação Básica (DEB) (2001). Currículo nacional do Ensino Básico - Competências essenciais. Lisboa: Ministério da Educação.

Departamento de Educação Básica (DEB) (2002). Ciências Físicas e Naturais Orientações curriculares para o $3^{\circ}$ Ciclo do Ensino Básico. Lisboa: Ministério da Educação.

Domingos, A. M. (1989). Conceptual demand of science courses and social class. In P. Adey (Ed.), Adolescent development and school science (pp. 211-223). Londres: Falmer Press.

Ferreira, S. (2007). Currículos e princípios ideológicos e pedagógicos dos autores Estudo do currículo de Ciências Naturais do $3^{\circ}$ Ciclo do Ensino Básico (Tese de mestrado). Lisboa: Universidade de Lisboa - Departamento de Educação da Faculdade de Ciências.

Ferreira, S., \& Morais, A. M. (2010). A natureza da ciência nos currículos de Ciências: Estudo do currículo de Ciências Naturais do $3^{\circ}$ Ciclo do Ensino Básico. Revista Portuguesa de Educação, 23(1), 119-156. 
Flores, M., \& Flores, M. (2000). Do currículo uniforme à flexibilização curricular: Algumas reflexões. In J. Pacheco, J. Morgado \& I. Viana (Orgs.), Actas do IV Colóquio sobre Questões Curriculares "Políticas curriculares: Caminhos da flexibilização e integração" (pp. 83-92). Braga: Universidade do Minho.

Fontes, A., \& Silva, I. (2004). Uma nova forma de aprender Ciências - A educação em Ciência/Tecnologia/Sociedade (CTS). Porto: Edições Asa.

Knain, E. (2001). Ideologies in school science textbooks. International Journal of Science Education, 23(3), 319-329.

Krathwohl, D. (2002). A revision of Bloom's taxonomy: An overview. Theory into practice, 41(4), 212-218.

McComas, W. F., Clough, M. P., \& Almazroa, H. (1998). The role and character of the nature of science in science education. In W. F. McComas (Ed.), The nature of science in science education: Rationales and strategies (pp. 3-39). Netherlands: Kluwer.

McComas, W. F., \& Olson, J. K. (1998). The nature of science in international science education standards documents. In W. F. McComas (Ed.), The nature of science in science education: Rationales and strategies (pp. 41-52). Netherlands: Kluwer.

Morais, A. M. (1991). Influência do nível de exigência conceptual dos professores no sucesso dos alunos em Ciências: Um estudo sociológico. Revista de Educação, II(1), 62-79.

Morais, A. M. (2002). Basil Bernstein at the micro level of the classroom - Looking at results of research. British Journal of Sociology of Education, 23(4), 559-569.

Morais, A. M., \& Miranda, C. (1995). O contexto de avaliação em Ciências: Estudo da influência de factores sociológicos. Revista Portuguesa de Educação, 8(2), 3767.

Morais, A. M., \& Neves, I. (2003). Processos de intervenção e análise em contextos pedagógicos. Educação, Sociedade \& Culturas, 19, 49-87.

Morais, A. M., \& Neves, I. P. (2007). Fazer investigação usando uma abordagem metodológica mista. Revista Portuguesa de Educação, 20(2), 75-104.

Morais, A. M., \& Neves, I. P. (2009). Textos e contextos educativos que promovem aprendizagem: Optimização de um modelo de prática pedagógica. Revista Portuguesa de Educação, 22(1), 5-28.

Neves, I. (1991). Contributos para uma análise sociológica de livros de texto. Revista de Educação, 1(2), 91-97.

Neves, I., \& Morais, A. M. (2001). Texts and contexts in educational systems: Studies of recontextualising spaces. In A. Morais, I. Neves, B. Davies \& H. Daniels (Eds.), Towards a sociology of pedagogy: The contribution of Basil Bernstein to research (pp. 223-249). Nova lorque: Peter Lang.

Neves, I. P., \& Morais, A. M. (2006). Processos de recontextualização num contexto de flexibilidade curricular - Análise da actual reforma das Ciências para o $3^{\circ}$ Ciclo do Ensino Básico. Revista de Educação, XIV(2), 75-94.

Pacheco, J. A. (2001). Currículo: Teoria e práxis (2a ed.). Porto: Porto Editora. 
Pires, D., Morais, A. M., \& Neves, I. P. (2004). Desenvolvimento científico nos primeiros anos de escolaridade: Estudo de características sociológicas específicas da prática pedagógica. Revista de Educação, XII(2), 119-132.

Santos, M. (2001). A cidadania na "voz" dos manuais escolares. Lisboa: Livros Horizonte.

Squire, J. (1992). Textbook publishing. In M. C. Alkin (Ed.), Encyclopedia of educational research, Vol. 4 (pp.1414-1420). Nova lorque: Macmillan.

Tashakkori, A., \& Creswell, J. W. (2007). The new era of mixed methods. Journal of Mixed Methods Research, 1(1), 3-7.

Valverde, G., Bianchi, L., Wolfe, R., Schmidt, W., \& Houang, R. (2002). According to the book - Using TIMSS to investigate the translation of policy into practice trough the world of textbooks. Netherlands: Kluwer Academic Publishers.

Vygotsky, L. (1978). Mind in society: The development of higher psychological processes. Cambridge: Harvard University Press.

Ziman, J. (1984). An introduction to science studies: The philosophical and social aspects of science and technology. Cambridge: Cambridge University Press. 


\section{CURRICULUM AND TEXTBOOKS IN A CONTEXT OF CURRICULAR FLEXIBILITY. ANALYSIS OF RECONTEXTUALIZING PROCESSES}

\section{Abstract}

This study analyses the message of two textbooks of the Natural Sciences curriculum for middle school, regarding specific pedagogic characteristics. It also analyses the recontextualizing processes that transform the science curriculum message in the textbook message. The study has epistemological, psychological and sociological theoretical bases. Bernstein's theory of pedagogic discourse is the main theoretical framework. A mixed methodology is used with dialectical process between the theoretical and the empirical. The results revealed that, in both textbooks, the metascience is poorly valued, there is a weak conceptual relation between knowledges, the conceptual demand is very low and the text to be transmitted/acquired is implicit. The textbook mostly selected by teachers had the lowest results. The recontextualizing processes changed the message contained in the science curriculum. These results raise questions about the level of scientific learning in a context of curricular flexibility, where textbooks' authors and teachers have greater control.

Keywords

Textbooks; Science education; Recontextualizing processes; Curricular flexibility

\section{PROGRAMMES ET MANUELS SCOLAIRES DANS LE CADRE DE LA FLEXIBILITÉ} DU CURRICULUM. ÉTUDE DES PROCESSUS DE RECONTEXTUALISATION

\section{Résumé}

L'étude analyse le message de deux manuels de Sciences Naturelles de 3 ème et 4 ème, et les processus de recontextualisation du message du curriculum qui se produisent dans la préparation des manuels scolaires, quand se considère 
des caractéristiques pédagogiques spécifiques. L'étude présente fondements épistémologiques, psychologiques et sociologiques et le principal cadre conceptuel de la recherche est le modèle du discours pédagogique de Bernstein. L'étude a utilisé une méthodologie mixte e a suivi un procès dialectique entre le théorique et l'empirique. Les résultats montrent que le message des deux manuels est de bas représentation par rapport a la metascience, de bas grade de relation intra-disciplinaire, d'exigence conceptuelle et de la clarification des critères d'évaluation, surtout le manuel le plus sélectionné. II y a un haut degré de recontextualisation du message du curriculum. Ces résultats soulèvent des questions sur le niveau de l'apprentissage scientifique dans le cadre de la flexibilité du curriculum, quand le contrôle est plus centré dans les auteurs des manuels scolaires et dans les enseignants.

Mots-clé

Manuels scolaires; Éducation scientifique; Processus de recontextualisation; Flexibilité du curriculum

Recebido em Outubro/2010 Aceite para publicação em Maio/2012 